\title{
Wizerunek stereotypowego Hiszpana w społeczeństwie polskim i hiszpańskim
}

\section{An image of a stereotypical Spaniard in Polish and Spanish society}

Aleksandra Wetna

(Bydgoszcz)

\begin{abstract}
The article deals with the subject matter of stereotypical image of Spaniard in Polish and Spanish tradition. The question of stereotyping, which, amongst other aspects, carries the knowledge of the world and mentality that is necessary in order to fully understand the culture of a given nation. has been dealt with by me in relation to the multiculturalism. What is the stereotypical image of Spaniard? Is our positive or negative attitude towards them reflected in the terminology we use to describe the Spanish? I have tried to answer these, and other, questions based on the survey carried out amongst Polish and Spanish students.
\end{abstract}

\section{Wstęp}

Dotychczasowe badania nad stereotypem ukazują interdyscyplinarny charakter tegoż zjawiska, które wciąż znajduje się w sferze zainteresowań socjologii, psychologii społecznej, historii literatury, kultury, a także komunikacji i lingwistyki (zob. Bartmiński 2007: $53 \mathrm{ff}$.). Na poczatku chcialabym przytoczyć cztery definicje stereotypu, na których oparte są moje dalsze rozważania. 
Stereotyp, istniejący jako element języka, przyczynia się do kreowania świata oraz ksztaltowania postaw danej wspólnoty komunikacyjnej (zob. Bartmiński 1993: 356). Stereotyp wg Uty Quasthoff to „sąd o przedmiocie niewynikajacy z obserwacji ani z definicji przedmiotu, ale z przekonań, przesąów lub wierzeń. Sąd taki może wplywać na dzialanie praktyczne ludzi nim się posługujących" (zob. Lewicki 1983: 18). Stereotypem wg Lippmana jest wreszcie „obraz przedmiotu w glowie ludzkiej, odnoszacy się do jakiegoś zjawiska spolecznego, jednostronny, schematyczny, zawierający też opinię o tym przedmiocie" (zob. Lewicki 1983: 18). Stereotyp może być również rozpatrywany jako niepisana umowa spoleczna, czyli konwencja i wtedy będzie nim każdy znak językowy (zob. Sawicka 1998: 147).

W tytule mojego referatu pojawia się pojęcie wizerunku, którego definicja zaproponowana przez Szarotę poszerza znaczenie stereotypu. Wedlug Szaroty „wizerunek (obraz) to uogólniająca ocena (sąd, opinia) na temat określonej grupy narodowej lub etnicznej, zawierająca $\mathrm{w}$ sobie obok elementów tradycyjnego stereotypu, także konstatacje wynikłe w wlasnych obserwacji i doświadczeń" (Szarota 1997: 91).

Analizując proces stereotypizacji, warto przyjrzeć się nazwanym przez Bartmińskiego „swoista choroba języka" stereotypom narodowym. Opierają się one na opozycji ,swój - obcy" i bardzo często powstają na bazie konfliktów (zob. Bartmiński 1993: 379), w związku z czym moga przyczynić się do zaburzeń w dialogu międzykulturowym rozumianym tu jako „porozumienie się w różny sposób ludzi przynależnych do odmiennych kultur" (Ratajczak 2006: 11). Oczywiśście nie należy zapominać, że negatywne oddzialywanie stereotypu nie determinuje jego istoty, ale stanowi jedynie jego aspekt. (zob. Quasthoff 1998: 19).

Podązając tokiem myślenia Bartmińskiego, którego definicja inicjuje moje rozważania, nie należy poprzez stereotypizację rozumieć wylącznie określeń (cech) dotyczących danej narodowości, ale również wszelkie sytuacje spoleczne, wytwory kultury, zwyczaje, a także przyrodę i symbole narodowe (zob. Bartmiński 1993: 365). Poprzez elementy budujace proces stereotypizacji manifestuje się również charakter narodowy (zob. Mikułowski-Pomorski 1999: 63f). 
Analizując istotę językowego stereotypu narodowego, warto przyjrzeć się jego funkcji kognitywnej, w myśl której proces rozumienia nie jest możliwy bez „wstępnej wiedzy”, uogólnień i „uprzedzeń". Tworzenie się stereotypów można przyrównać do tworzenia się schematów Bartletta-podobnie jak stereotypy powstających prymarnie w toku socjalizacji (zob. Quasthoff 1998: 14ff.). $\mathrm{Na}$ początku moich rozważań przywołalam definicję stereotypu wg Lippmana, która określa stereotyp mianem obrazu w glowie. Odwolując się do koncepcji schematu Bartletta, ów obraz w głowie można uznać za schemat, czyli za

niejęzykową poznawczą strukturę funkcjonującą w pamięci czlowieka, w której na podstawie doświadczeń otrzymaly swoją reprezentację typowe powiązania wewnątrz jakiegoś obszaru rzeczywistości. Schematy łączą pojęcia dotyczące przedmiotów, stanów, zdarzeń i czynności. (Quasthoff 1998: 15).

Do jakiego stopnia obraz (schemat) stereotypowego Hiszpana widziany oczami Polaków i Hiszpanów jest podobny? Czy różnice w postrzeganiu Hiszpanów przez nich samych i przez nas są tak duże, że moga zaburzać dialog międzykulturowy? W jaki sposób szeroko pojęta terminologia dotycząca symboli oraz cech kojarzacych się z Hiszpanią odzwierciedla nastawienie spoleczności polskiej do hiszpańskiej? Jak postrzegamy kulturę i mieszkańców Hiszpanii i w jaki sposób nasze uprzedzenia bądź sympatie przejawiają się w języku?

\section{Cel badań}

Kontakty między Hiszpanią a Polską przez stulecia ograniczały się do jednostkowych podróży osobistych - czy to dyplomatycznych, wojskowych, czy turystycznych. Znaczace zmiany w tych relacjach nastapily pod koniec XX w. Wejście do Unii Europejskiej zarówno Hiszpanii (1986), jak i Polski (2004) przyczynilo się do widocznego ożywienia w sferze gospodarczej (firmy hiszpańskie 
rozpoczęly dzialalność na rynku polskim), społecznej (migracje, podróże turystyczne), kulturalnej (powstanie Instytutu Cervantesa w Warszawie, program edukacyjne Sokrates i Erasmus) (zob. Gonzalez/Nalewajko 2003: 5).

W obliczu zmian, które przyniosła ze sobąintegracja europejska, postanowilam poświęcić moje badania porównaniu autostereotypu z heterostereotypem Hiszpanów, a także zbadać czy stereotypowy wizerunek tej nacji ma widoczne odzwierciedlenie w symbolach kojarzacych się obu badanym grupom z Hiszpanią.

\section{Metody i przebieg badań}

Sporzadzona przeze mnie ankieta badawcza dotyczaca stereotypu Hiszpanów zostala przeprowadzona wśród 50 studentów z Polski i 50 z Hiszpanii. W celu zbadania odniesień wizerunku stereotypowego Hiszpana do symboli/obrazów kojarzacych się z Hiszpania, zdecydowalam się na wprowadzenie dwóch typów zadań.

Zbadanie treści ewaluatywnych stereotypów umożliwiło zastosowanie skal interwałowych, na biegunach których znalazly się opozycyjne cechy, dlatego też w celu stworzenia karty dyferencjału semantycznego, skorzystałam z metody Osgooda z zastosowaniem siedmiopunktowej skali. Skala zostala zinterpretowana lingwistycznie, wartości 1,2, 3 zostały utożsamione ze stopniami przymiotnika 1 „trochę”, 2 „bardziej”, 3 „,najbardziej” (zob. Bartmiński 2007: 76ff.). Pomiędzy biegunami został umieszczony punkt 0 , którego znaczenie jest równoznaczne $z$,,ani taki, ani taki”. Na sporządzonej przeze mnie karcie dyferencjału semantycznego znajduje się 37 par cech opozycyjnych (zob. tabela 1.). Wśród wyselekcjonowanych cech narodowości 10 (1-10) przedstawia wlaściwości psychiczne $\mathrm{i}$ intelektualne, 5 (11-15) to cechy bytowe, 18 (16-33) cechy spoleczne oraz 4 (34-37) postawy wobec świata i ojczyzny.

W drugim zadaniu, które wprowadzilam do ankiety, respondenci poproszeni zostali o wymienienie symboli kojarzących im się z Hiszpanią i Hiszpanami. 


\section{Wyniki}

W tabeli 1. zostaly podane w procentach dane ankietowe dotyczące autostereotypu i heterostereotypu Hiszpanów. Wyniki kwestionariuszy pokazują, że mimo niezbyt intensywnych kontaktów pomiędzy dwoma krajami, odpowiedzi polskich i hiszpańskich ankietowanych są bardzo zbliżone. W opinii studentów obu narodowości, pod względem właściwości psychicznych, Hiszpanie jawią się jako naród wesoly i uczuciowy, jak również zarozumiały, spóźnialski i lekkomyślny. Odwaga i temperament sa cechami częściej wybieranymi przez respondentów polskich $(35 \%$ odwaga, $79 \%$ temperament). Intelekt polscy i hiszpańscy ankietowani ocenili niemal identycznie - Polacy nieco wyżej.

Spośród pięciu par wyrażeń określających postawę życiową oraz stosunek do dóbr materialnych, cechy rozrzutny, przedsiębiorczy i pijący zostaly wytypowane zarówno przez studentów hiszpańskich, jak i polskich. W opinii Polaków Hiszpanie są narodem bogatym i leniwym, podczas gdy oni sami oceniają siebie jako biednych i ani leniwych, ani pracowitych.

Różnice w sposobie postrzegania badanej przeze mnie nacji dotyczą również postaw wobec świata i ojczyzny. Hiszpanie widzą siebie jako zdecydowanie bardziej wierzacych $(27 \% \mathrm{H}, 6 \% \mathrm{P})$ i mniej patriotycznych $(21 \% \mathrm{H}, 43 \% \mathrm{P})$. W oczach Polaków badany naród jest liberalny, w oczach Hiszpanów konserwatywny.

Wyniki badań pokazują że stosunek Hiszpanii do innych ludzi (cechy spoleczne) wedlug spoleczeństwa polskiego i hiszpańskiego nieco różni się od siebie. Przez Polaków Hiszpanie zostali ocenieni jako lagodni, agresywni i troskliwi. Hiszpanie natomiast wytypowali cechy opozycyjne: brutalni, spokojni i ignoranci. Ponad dwudziestoprocentowe różnice pojawily się również przy wyborze cech: zazdrosny $(13 \% \mathrm{H}, 35 \% \mathrm{P})$, uczynny $(30 \% \mathrm{H}, 13 \% \mathrm{P})$, bezpośredni $(19 \% \mathrm{H}, 63 \%$ P) i glośny $(28 \%$ H, $75 \%$ P). Zarówno studenci hiszpańscy, ja i polscy byli zgodni przy wyborze 10 cech spolecznych. Wedlug obu grup Hiszpanie sa: towarzyscy, otwarci, uparci, szczerzy, niezależni, kulturalni, uczciwi, tolerancyjni, namiętni i przesąni. 
W tabeli 2. i 3. umieszczone zostaly symbole, kojarzące się z Hiszpanią i Hiszpanami, o których wymienienie zostali poproszeni ankietowani. Zdecydowalam się umieścić 15 najczęściej przywolywanych przez respondentów symboli. Zadanie to, jak wspomnialam wcześniej, mialo na celu uzupehnienie, dookreślenie wizerunku Hiszpanów. Polakom Hiszpania kojarzy się przede wszystkim z walką byków - corridq. Wśród studentów hiszpańskich corrida nie pojawia się często, ale dużą frekwencję ma symbol byka. Warto zwrócić uwagę na fakt, że polscy respondenci określają Hiszpanów mianem agresywnych, natomiast oni sami widzą siebie jako naród brutalny. Tradycja zabijania byków ma zapewne ogromny wplyw na wspólczesny wizerunek badanej nacji.

Innym zwyczajem, który polskim ankietowanym kojarzyl się z Hiszpanami jest la tomatina, czyli walka na pomidory. Zarówno studenci hiszpańscy, jak i polscy wśród symboli kojarzacych się z Hiszpanią wymienili fiesty czyli zabawy. Dopelnieniem obrazu bawiących się ludzi jest przywolywane zarówno przez hiszpańskich, jak i polskich ankietowanych flamenco.

Analizując pozytywne nastawienie do życia Hiszpanów, warto zaznaczyć, że niezaprzeczalnie lączy się ono z plażq, morzem, slońcem i palmami - symbolami przywolanymi przez respondentów polskich i hiszpańskich.

Ważnym dla Hiszpanów, ominiętym przez polskich ankietowanych zwyczajem hiszpańskim jest poobiednia drzemka tzw. sjesta. Zaskakujący jest brak tegoż symbolu w odpowiedziach Polaków, ponieważ samo słowo sjesta można już wlaściwie uznać za zapożyczenie z języka hiszpańskiego. W języku polskim słowo „sjesta” jest wykorzystywane jako synonim krótkiej drzemki, wypoczynku (Slownik Języka Polskiego 1981: 221). Duża popularnością wśród ankietowanych cieszyly się również potrawy ${ }^{1}$.

Podczas omawiania wyników dotyczących symboli, warto zwrócić uwagę na fakt, iż studenci polscy utożsamiają Hiszpanię także z popularnymi z różnych względów (turystycznych, kulturalnych, politycznych, sportowych) miastami - w ankietach pojawil się $M a-$ dryt oraz Barcelona. Wśród hiszpańskich respondentów jedynym

Wśród wymienionych przez ankietowanych tradycyjnych hiszpańskich potraw znalazły się: tortilla, paella, jamon, tapas. 
symbolem odnoszącym się do kultury jest postać Don Quijote, który z kolei zostal pominięty przez Polaków.

\section{Wnioski}

Z przeprowadzonych przeze mnie badań wynika, że Polacy mają bardzo sprecyzowane opinie na temat Hiszpanów. Według tabeli 1., 16 cech zostało wytypowanych przez więcej niż $30 \%$ ankietowanych, 8 przez więcej niż $50 \%$, a 4 przez więcej niż $70 \%$ respondentów. Przymiotniki kojarzące się z Hiszpanami, które wybierano najczęściej to: towarzyski ( $95 \%)$, wesoly $(88 \%)$, otwarty (87\%), temperamenty (79\%) i uczuciowy (68\%). Stereotypowy Hiszpan jest przez Polaków utożsamiany glównie z emocjami. Wlaściwości psychiczne oraz cechy spoleczne okazaly się dla respondentów kluczowe dla określenia Hiszpanów. Owa „uczuciowość” ma swoje odbicie również w wymienianych przez ankietowanych symbolach kojarzących się z badanym narodem. Pojawienie się hiszpańskiej tradycji (la tomatina, corrida), muzyki (flamenco), atakże przyrody i klimatu (słońce, plaża, palmy) wskazują na owa wcześniej wspomniana ,uczuciowość”. Posilkując się wynikami badań, widać również, że w oczach Polaków Hiszpania to nie tylko kraj słońca i pięknych plaż. Postrzegamy go również od strony kulturalnej, kojarzy się nam z wielowiekową tradycją oraz kulturą wspólczesną.

Podobnie jak ankietowani polscy, Hiszpanie oceniaja siebie jako wesolych (96\%), uczuciowych (71\%), towarzyskich (84\%), otwartych (75\%) i namiętnych (65\%). Ponownie zatem wizerunek stereotypowego Hiszpana będzie glównie kojarzony z emocjami i uczuciowościa, tym bardziej, że szczęście i dobry humor pojawily się jako symbole kojarzace się z Hiszpanią.

Badania przeprowadzone wśród studentów polskich i hiszpańskich pokazuja zdecydowanie pozytywny stosunek obu grup społecznych do badanej nacji. Spośród 37 par opozycyjnych Polacy przypisali badanej nacji 27 cech pozytywnych i 10 negatywnych, natomiast Hiszpanie 12 negatywnych i 25 pozytywnych. 


\section{Bibliografia}

Bartmiński, Jerzy/Panasiuk Jolanta (1993): „Stereotypy językowe”. [w:] Bartmiński, Jerzy (red.): Wspókczesny język polski. Encyklopedia kultury polskiej XX wieku t.II. Wroclaw: Wiedza o kulturze, 363-387.

Batmiński, Jerzy (2007): „Stereotyp jak przedmiot lingwistyki”. [w:] Bartmiński, Jerzy (red.): Stereotypy mieszkajq w języku. Studia etnologiczne. Lublin: Wydawnictwo UMCS, 53-241.

Folch Borja/López-Guerrero Gabriel Calvo (1995): Hiszpania odMadrytu po Morze Śródziemne i Baleary. Warszawa: Nelles.

Gonzalez, Elda/Nalewajko, Malgorzata (red.) (2003): Hiszpania-Polska spotkania. Warszawa: Neriton.

Lewicki, Andrzej (1985): „Motywacja globalna frazeologizmów. Znaczenie przenośne, symboliczne i stereotypowe". [w:] Basaj, Mieczyslaw/Kuc. Danuta (red.): Wroclaw: Zakład Narodowy im. Ossolińskich, 7-23.

Mikułowski Pomorski, Jerzy (1999), Komunikacja międzykulturowa: wprowadzenie. Kraków: Wydawnictwo Akademii Ekonomicznej w Krakowie.

Quasthoff, Uta (1998): „Etnocentryczne przetwarzanie informacji. Ambiwalencja funkcji stereotypów w komunikacji międzykulturowej”. [w:] Anusiewicz, Janusz/Bartmiński, Jerzy (red.): Język a kultura t.12. Wroclaw: Towarzystwo Przyjaciół Polonistyki Wrocławskiej, 10-30.

Ratajczak, Magdalena (2006): „Komunikacja międzykulturowa - wybrane zagadnienia”. [w:] Ratajczak, Magdalena (red.): Pomiędzy kulturami: szkice z komunikacji międzykulturowej. Wroclaw: Wydawnictwo Uniwersytetu Wrocławskiego, 11-21.

Sawicka, Grażyna (1998): „Funkcje stereotypu w nominacji językowej”. [w:] Anusiewicz, Janusz/Bartmiński, Jerzy (red.): Język a kultura t.12. Wroclaw: Towarzystwo Przyjaciół Polonistyki Wroclawskiej, $146-154$.

Szarota, Tomasz (1997): , Polak w karykaturze niemieckiej (1914-1944). [w:] Bokszański, Zbigniew: Stereotypy a kultura. Wroclaw: Wydawnictwo Fundacji dla Uniwersytetu Wroclawskiego.

Szymczak, Mieczysław (red.) (1981): Stownik Języka Polskiego. Warszawa: Polskie Wydawnictwo Naukowe. 


\section{Tabela 1}

\begin{tabular}{|c|c|c|c|c|}
\hline Ip. & + & - & $\begin{array}{l}\text { Autoste- } \\
\text { reotyp }\end{array}$ & $\begin{array}{c}\text { Heteroste-re- } \\
\text { otyp }\end{array}$ \\
\hline & & & \multicolumn{2}{|c|}{ dane $w \%$} \\
\hline 1 & odważny & tchórzliwy & 13 & 35 \\
\hline 2 & wesoły & smutny & 96 & 88 \\
\hline 3 & skromny & zarozumiały & -41 & -37 \\
\hline 4 & uczuciowy & chłodny, & 71 & 68 \\
\hline 5 & inteligentny & tępy & 25 & 25 \\
\hline 6 & wykształcony & niewykształcony & 14 & 19 \\
\hline 7 & mądry & głupi & 15 & 19 \\
\hline 8 & punktualny & spóźnialski & -38 & -57 \\
\hline 9 & temperamentny & flegmatyczny & 52 & 79 \\
\hline 10 & rozważny & lekkomyślny & -10 & -26 \\
\hline 11 & pracowity & leniwy & 0 & -38 \\
\hline 12 & przedsiębiorczy & niezaradny & 14 & 13 \\
\hline 13 & oszczędny & rozrzutny & -14 & -26 \\
\hline 14 & zamożny & biedny & -3 & 11 \\
\hline 15 & niepijący & pijak & -51 & -46 \\
\hline 16 & towarzyski & nietowarzyski & 84 & 95 \\
\hline 17 & otwarty & zamknięty & 75 & 87 \\
\hline 18 & uparty & uległy & 61 & 47 \\
\hline 19 & szczery & fałszywy & 30 & 36 \\
\hline 20 & niezależny & ulegly & 25 & 31 \\
\hline 21 & kulturalny & niekulturalny & 5 & 18 \\
\hline 22 & uczciwy & nieuczciwy & 25 & 10 \\
\hline 23 & łagodny & brutalny & -2 & 5 \\
\hline
\end{tabular}


Aleksandra Welna

\begin{tabular}{|c|l|l|c|c|}
\hline 24 & tolerancyjny & nietolerancyjny & 26 & 36 \\
\hline 25 & spokojny & agresywny & 7 & -14 \\
\hline 26 & stonowany & głośny & -28 & -75 \\
\hline 27 & honorowy & niehonorowy & 32 & 36 \\
\hline 28 & namiętny & chłodny & 65 & 65 \\
\hline 29 & bezpośredni & dyplomatyczny & 19 & 63 \\
\hline 30 & racjonalny & przesądny & -14 & -15 \\
\hline 31 & uczynny & egoista & 30 & 13 \\
\hline 32 & troskliwy & ignorant & -7 & 18 \\
\hline 33 & wyrozumiały & zazdrosny & -13 & -35 \\
\hline 34 & liberalny & konserwatywny & -5 & 14 \\
\hline 35 & patriotyzm & brak patriotyzmu & 21 & 43 \\
\hline 36 & wierzący & niewierzący & 27 & 6 \\
\hline 37 & nacjonalizm & kosmopolityzm & 34 & 19 \\
\hline & & & & \\
\hline
\end{tabular}

Tabela 2

\begin{tabular}{|c|l|l|}
\hline Ip. & \multicolumn{1}{|c|}{ symbole } & liczba odpowiedzi \\
\hline 1. & stońce & 25 \\
\hline 2. & byk & 24 \\
\hline 3. & plaża & 21 \\
\hline 4. & gitara & 21 \\
\hline 5. & jamon & 20 \\
\hline 6. & paella & 19 \\
\hline 7. & wino & 18 \\
\hline 8. & tortilla & 17 \\
\hline 9. & tapas & 17 \\
\hline
\end{tabular}


Wizerunek stereotypowego Hiszpana w spoleczeństwie polskim i hiszpańskim

\begin{tabular}{|c|l|l|}
\hline 10. & siesta & 12 \\
\hline 11. & fiesta & 11 \\
\hline 12. & szczęście & 8 \\
\hline 13. & dobry humor & 5 \\
\hline 14. & Don Kichote & 5 \\
\hline 15. & flamenco & 3 \\
\hline
\end{tabular}

Tabela 3

\begin{tabular}{|c|l|l|}
\hline Ip. & \multicolumn{1}{|c|}{ symbole } & liczba odpowiedzi \\
\hline 1. & corrida & 30 \\
\hline 2. & flamenco & 27 \\
\hline 3. & stońce & 22 \\
\hline 4. & tortilla & 15 \\
\hline 5. & Barcelona & 12 \\
\hline 6. & byk & 12 \\
\hline 7. & wino & 9 \\
\hline 8. & Madryt & 9 \\
\hline 9. & plaża & 9 \\
\hline 10. & paella & 7 \\
\hline 11. & tomatina & 7 \\
\hline 12. & fiesta & 6 \\
\hline 13. & Pedro Almodovar & 6 \\
\hline 14. & palmy & 5 \\
\hline 15. & morze & 5 \\
\hline
\end{tabular}

